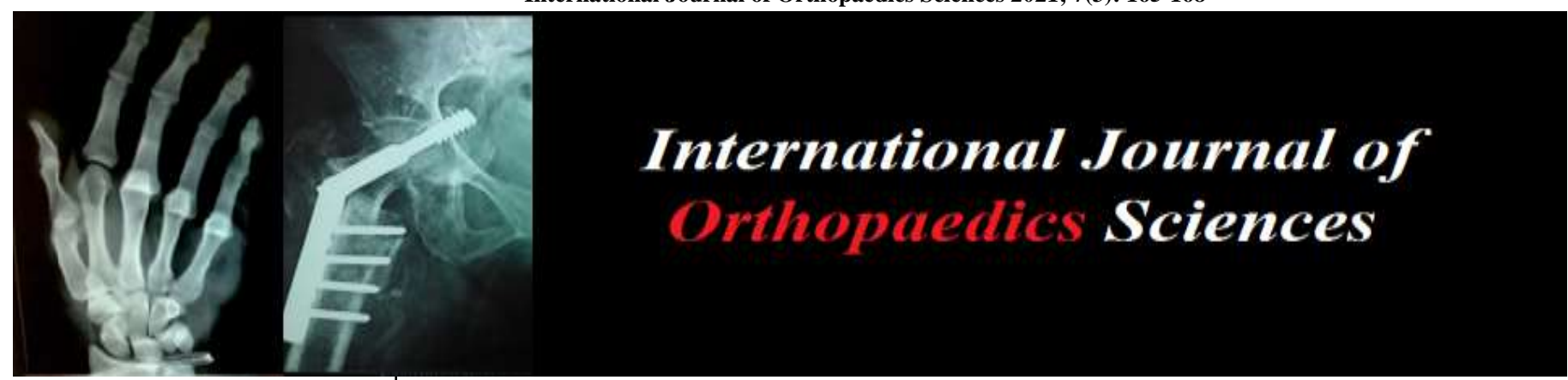

E-ISSN: 2395-1958

P-ISSN: 2706-6630

IJOS 2021; 7(3): 165-168

(C) 2021 IJOS

www.orthopaper.com

Received: 19-04-2021

Accepted: 07-06-2021

Dr. Vijayakumar S Kulambi

Professor, Department of

Orthopaedics, J.J.M. Medical

College, Davangere, Karnataka,

India

Dr. Raghukumar

Professor, Department of

Orthopaedics, J.J.M. Medical

College, Davangere, Karnataka,

India

Dr. Subodh Shetty

Professor, Department of Orthopaedics, J.J.M. Medical

College, Davangere, Karnataka, India

Dr. Sabarish K

Junior Resident, Department of Orthopaedics, J.J.M. Medical College, Davangere, Karnataka, India
Corresponding Author:

Dr. Sabarish K

Junior Resident, Department of Orthopaedics, J.J.M. Medical College, Davangere, Karnataka, India

\section{Prospective study of surgical management of proximal tibia fracture with locking compression plate using minimally invasive percutaneous plate osteosynthesis technique}

\author{
Dr. Vijayakumar S Kulambi, Dr. Raghukumar, Dr. Subodh Shetty and \\ Dr. Sabarish K
}

DOI: https://doi.org/10.22271/ortho.2021.v7.i3c.2741

Abstract

Introduction: The majority of tibial plateau fractures are secondary to high velocity road traffic accidents. Hence the management of high-energy proximal tibial fractures will need very good care of the soft-tissue envelope as the surface of the proximal tibia is covered only with skin and subcutaneous tissues The main goal of surgical treatment of proximal tibial fractures in this study is to restore and preserve normal knee function by using Minimally Invasive Percutaneous Plate Osteosynthesis (MIPPO) technique.

Method: 32 cases of proximal tibial fractures from Chigateri General Hospital and Bapuji Hospital attached to J.J.M Medical College, Davangere during the study period were included in study and cases were followed up for a minimum period of 12 months. At 4, 6, 9, 12, 16 weeks and then two monthly follow up till 12 months. Inability to take part in post operative rehabilitation \& those with Open fractures were excluded from the study.

Result: Based on Modified Rasmussen criteria for clinical assessment in our study we achieved $71.88 \%$ excellent results, $15.62 \%$ good results (with overall of $87 . \%$ excellent to good results) and $12.5 \%$ fair results.

Keywords: Surgical management, proximal tibia, plate osteosynthesis technique

\section{Introduction}

Proximal tibia is involved in transmission of body weight through the knee joint and it also has a key role in the knee function and stability. Severe bone and soft tissue injuries are not infrequent and there is high incidence of open fracture compared with other long bones because of limited soft tissue cover and less vascularity ${ }^{[1]}$.

The common cause of tibial plateau fractures are secondary to high velocity road traffic accidents ${ }^{[2]}$ and fall from height where fractures result from direct axial compression, usually with a valgus (more common) or varus movement and indirect shear forces ${ }^{[3]}$.

The main goal of surgical treatment of proximal tibial fractures is to restore and preserve normal knee function, which can be accomplished by anatomical restoration of articular surfaces, maintaining mechanical axis, restoring ligamentous stability and preserving a functional pain free range of motion of knee using Minimally Invasive Percutaneous Plate Osteosynthesis (MIPPO) technique.

With the gradual changes in the treatment modalities of fracture proximal end of tibia from conservative measures like cast bracing, traction, immobilization to surgical intervention for better results. There is a need for better conservative minimal invasive surgery and better fracture fixation technique in view of complications associated with conventional plates screw system, radical exposure of fracture site and inherent fracture and soft tissue injury.

With the better understanding of fracture healing biology and biomechanics of fracture fixation and healing, there is evolution of new concept of fracture fixation with fixed angular stable plate, (internal fixator, LCP) and minimally invasive surgical techniques.

The trend of treatment is towards biological fixation, which can be accomplished by LCP and MIPPO technique ${ }^{[4]}$. 


\section{Objectives of the Study}

- To assess anatomy of articular surface of upper end of tibia and knee joint following the surgery

- To assess the union of fractures after internal fixation.

- To assess the functional outcome of knee joint with early mobilization and the range of motion of knee joint after surgical management.

\section{Materials and Methods}

Adults aged $>18$ years with proximal tibial fractures admitted to Chigateri General Hospital and Bapuji Hospital attached to J.J.M Medical College, Davangere in the period from October 2018 to January 2021. 32 cases of proximal tibial fractures from Chigateri General Hospital and Bapuji Hospital attached to J.J.M Medical College, Davangere during the study period were included in study, and cases were followed up for a minimum period of 12 months. At 4,6,9,12,16 weeks and then two monthly follow up till 12 months. Patients with age $<18$ yrs, Medical contraindications for surgery, Inability to take part in post operative rehabilitation \& those with Open fractures were excluded from the study. A thorough clinical examination was carried out. The initial radiographs included AP and Lateral view of tibia with knee joint. Patient and the family is then explained about the nature of the fracture, prognosis of non operative and operative treatment and also regarding the need for closed/open reduction and internal fixation in their case. The patient and his family members were explained about the study and consent was taken if they agree to be a part of the study.

\section{Inclusion criteria}

- Patients with proximal tibial fractures aged 18 years and above

\section{Exclusion criteria}

- Patients with Open proximal tibial fractures

- Patients with pathological proximal tibial fractures other than osteoporosis

- Proximal tibial fractures with neurovascular deficit and other medical reasons

\section{Operative Technique}

The surgery was performed with the patient under spinal or epidural anesthesia. The patient was placed supine on a radiolucent fracture table. A pneumatic tourniquet cuff with adequate padding was applied to the proximal thigh. The limb was thoroughly scrubbed primarily with betadine scrub solution, painted and draped. The operative site and exposed portion were covered with a sterile towel and the limb exsanguinated with a sterile Esmarchs bandage and the

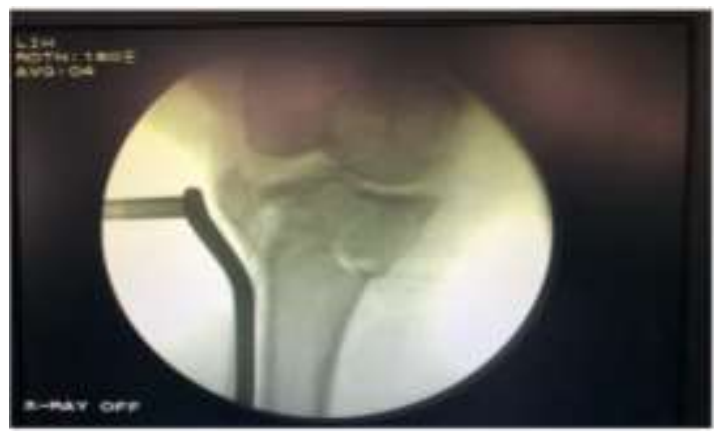

tourniquet inflated, after which the operative site was painted with betadine and then with surgical spirit. With the help of an image, intensifier closed reduction was achieved. In certain cases, percutaneous k-wires and condylar clamps were introduced to aid in fracture alignment also in case of depression type of fractures condylar elevators were used to restore the joint congruity. Standard lateral incision was made. A tunnel was made submuscularly with the help of Cobb's elevator. Pre-contoured anatomical locking compression plates of $4.5 \mathrm{~mm}$ from 5 to 11 holes length were used in all cases. The plate was passed through this tunnel with the help of an image intensifier. Each fragment was fixed on either side with a purchase of minimum six cortices. Strength of fixation was assessed intraoperatively by gentle movement of knee and ankle joints. Every measure was taken to cover the bone and plate with soft tissue at least without tension. Wound was closed in layers.

Postoperative radiograph was taken on the 2nd or 3rd postoperative day. Non Weight bearing physiotherapy was advised to the patients.

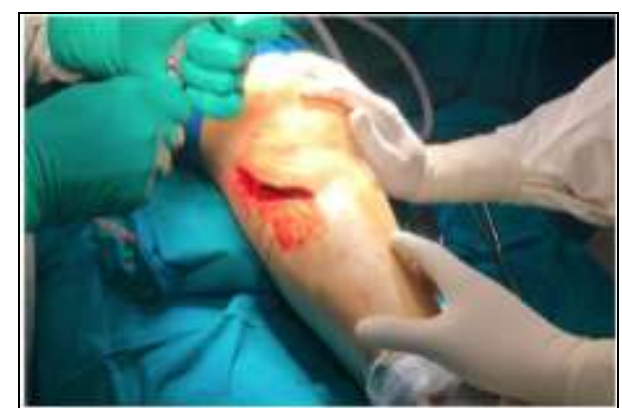

Fig 1: Lateral incision

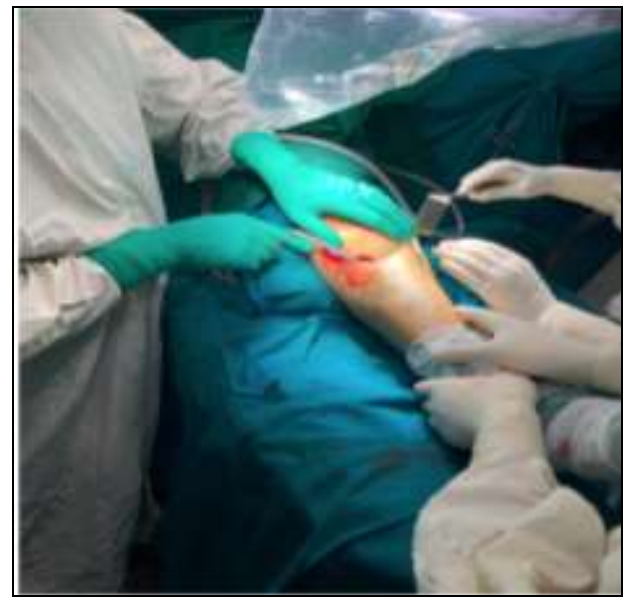

Fig 2: Sliding of the plate

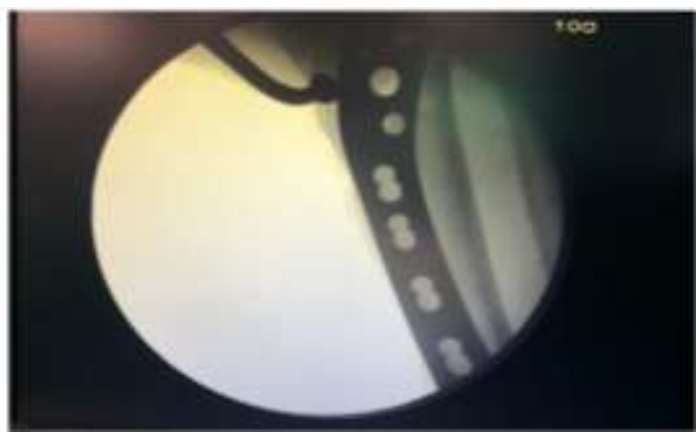

Fig 3: Position of the plate in AP and lateral views 


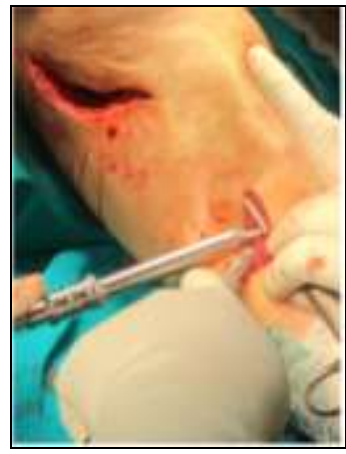

Fig 4: Distal locking.

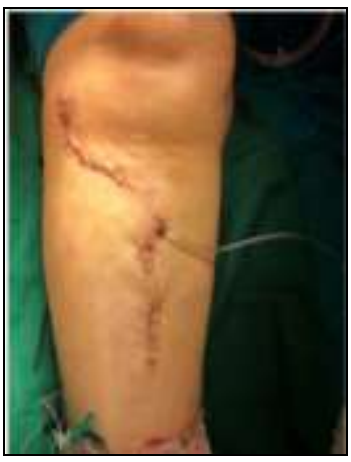

Fig 5: Wound closure.

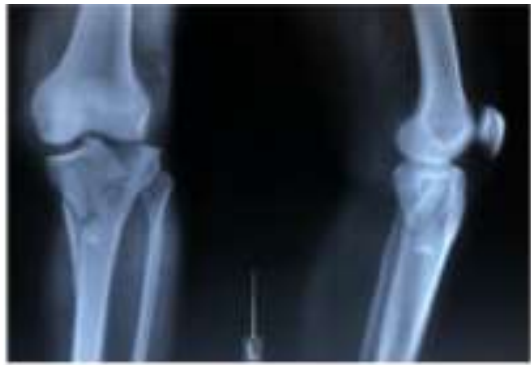

Pre op X-ray

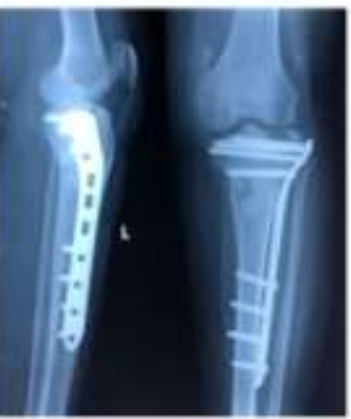

6 weeks post op

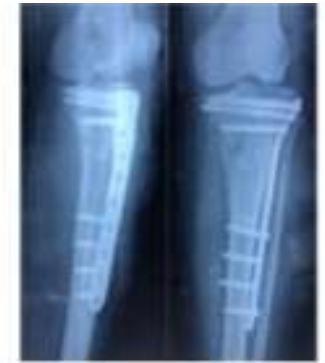

Post op X-ray

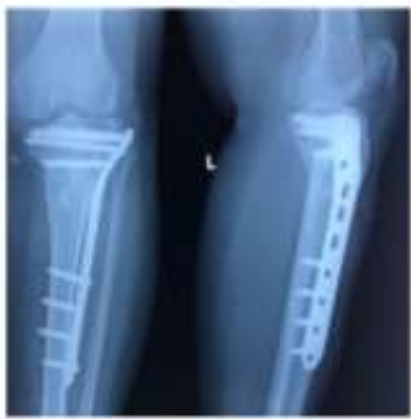

6 months post op

Where stable internal fixation was achieved, the patient was mobilized after 48 hours. For 2-3 day, the range of motion allowed was 0-20 degree, then the range of motion was gradually allowed to be increased after suture removal. Whenever there was doubt about the stable fixation, external splinting (Plaster of Paris slab) was given for support and advised to do static quadriceps exercises. Patients were discharged after 7-15 days of operation depending on wound healing. Partial weight bearing was delayed till 6 weeks and full weight bearing allowed after 12-15 weeks.

During each follow-up, cases were assessed and examined for skin condition, sign of any superficial and deep infection, plate and bone exposure, range of knee and ankle movement, rest and activity pain. Routine follow-up radiograph was obtained every 6 weeks until solid bridging callus formation was observed.

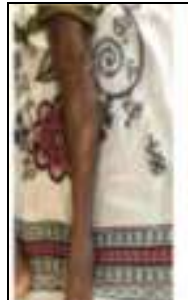

\section{.}

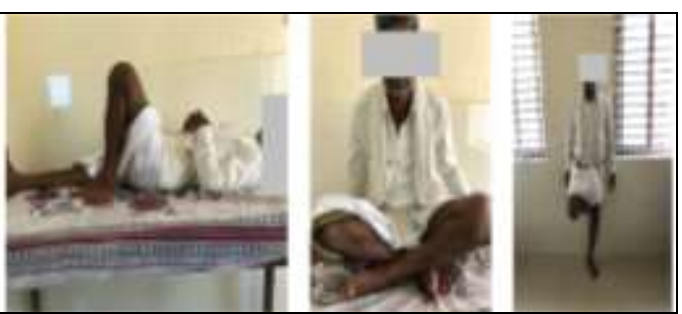

Fig 6: Clinical Pictures

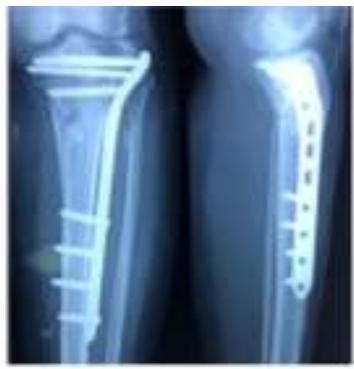

4 weeks post op

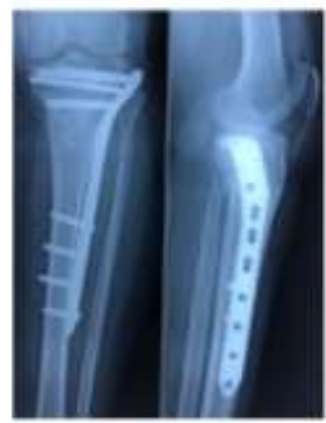

1 year post op

Fig 7: Radiological evaluation

\section{Result}

This is a study of 32 cases of tibial plateau fracture of patients age more than 18 years treated with proximal tibial LCP using MIPPO technique. Patients of this study were followed up regularly upto a period of one year. Of the patients participated in this study they were in the age group 22 to 75 years. Majority of the patients were male $22(68.75 \%)$ and 10 female $(31.25 \%)$. The major reason for fractures in our study was trauma caused by road traffic accidents $26(18.75 \%)$ and 6 self fall $(18.75 \%)$.

In our study all the fractures studied were closed types of fractures. According to Schatzker's classification we had 10 Type 1 fractures $(31.25 \%), 15$ Type 2 fractures (46.88\%), 4 Type 4 fractures $(12.5 \%), 1$ Type 5 fracture $(3.12 \%)$ and 2 Type 6 fractures $(6.25 \%)$. The complications encountered in our study were knee stiffness 3 patients $(9.38 \%)$ who were treated with physiotherapy and 3 patients with superficial infection $(9.38 \%)$ who were treated with antibiotics and regular dressing.

\section{Discussion}

Tibial plateau fractures are one of the common fracture that 
we see in any trauma setup and tibia being a major weight bearing bone, the need for achieving maximal functional outcome should be the goal of the treating surgeon. But due the increase in high velocity impacts the complexity of the fracture also changed. The goal of treatment is to restore the joint congruity, limb alignment and early mobilization. Treating modalities of proximal tibia fractures are numerous ranging from cast bracing to operative options like plate and screws, screw alone, external fixation, IM nailing. There is a need for better conservative minimal invasive surgery and better fracture fixation technique in view of associated complications. In our study of 32 proximal tibial fractures we chose to use tissue friendly approach (MIPPO) and better plates (LCP) for fixing the fractures.

In our study age and sex distribution directly correlates to the mode of injury being road traffic accident and the population at risk are the males who are often involved in travelling activities. Reddy JPK et al. ${ }^{[5]}$ in their study came to a conclusion that the incidence of fracture was more common in male which is most likely due to occupational and ambulant life led by them. Most common mode injury is road traffic accident. Patil DG et al. ${ }^{[6]}$, Barei DP et al. ${ }^{[7]}$ and Dendrinos GK et al. ${ }^{[8]}$ also concluded that among modes of injury, road traffic accidents are the most common. Majority of the fractures we encounter in our study belongs to Type 1 (10 cases) and Type 2 (15 cases) of Schatzker classification. Postoperative complications that we encountered in our study were surgical wound infection and knee stiffness. 3 cases of superficial surgical wound infection were treated aggressively with culture specific antibiotic and regular dressing. We did not encounter any wound dehiscence as post op or late compilation. Knee stiffness occurred in 3 cases and was treated with physiotherapy of which 2 cases it returned to more than 90 degree and one case it returned to 60 degrees. Cases were followed up to a period of 1 year and knee stiffness and superficial infection are the only complication that was encountered. Average fracture union period noted in our study was $12-16$ weeks. In the study conducted by Reddy JPK et al. ${ }^{[5]}$ average union time was 12 to 20 weeks and in the study by Kancherla NR et al. ${ }^{\text {[9] }}$ average union time was 19 weeks ranging from 16 to 24 weeks. No malunion in valgus or varus, non-union, implant failure or secondary osteomyelitis was seen in our study. Based on Modified Rasmussen criteria for clinical assessment in our study we achieved $71.88 \%$ excellent results, $15.62 \%$ good results (with overall of $87.5 \%$ excellent to good results) and $12.5 \%$ fair results.

These results are comparable with other documented standard studies.

\section{Conclusion}

At the end of our study we conclude that fractures that were treated with early fixation and early mobilization show better functional outcomes. Even though our study has only a small group of patient, we can say that treating the tibial plateau fractures with LCP using MIPPO technique is an effective method of treatment considering the complexity of the fractures due to high energy impacts and the soft tissue coverage of the tibia.

\section{References}

1. Kenneth Egol A, Kenneth Koval J. In: Fractures of proximal tibia: chapter 50, Rockwood and Green's "Fractures in Adults", $6^{\text {th }}$ edition, Lippincott Williams and Wilkins 2.
2. Schulak DJ, Gunn DR. Fracture of the tibial plateaus. Clin Orthop 1975;109:166-177.

3. Koval KJ, Hulfut DL. Tibial plateau fracture: evaluation and treatment. J Am Acad Orthop Surg 1995;3(2):86-94.

4. Stoffel Dietaru K. Biomechanical testing of the LCP how can stability in locked internal fixator be controlled? Injury 2003;34(2):B11-9.

5. Reddy JP, Nazeer BS, Arun HS, Kumar NM. Study of surgical management of proximal tibial fractures using locking compression plate. International Journal of Biomedical and Advance Research 2016;7(3):123-7.

6. Patil DG, Ghosh S, Chaudhuri A, Datta S, De C, Sanyal P. Comparative study of fixation of proximal tibial fractures by nonlocking buttress versus locking compression plate. Saudi Journal of Sports Medicine 2015;15(2):142.

7. Barei DP, Nork SE, Mills WJ, Coles CP, Henley MB, Benirschke SK. Functional outcomes of severe bicondylar tibial plateau fractures treated with dual incisions and medial and lateral plates. JBJS 2006;88(8):1713-21.

8. Dendrinos GK, Kontos S, Katsenis D, Dalas A. Treatment of high-energy tibial plateau fractures by the Ilizarov circular fixator. The Journal of bone and joint surgery. British 1996;78(5):710-7.

9. Kancherla NR, Hussain KS, Sreenath M, Chilakamarri VK. Outcome of treatment of proximal tibial plateau fractures by minimally invasive percutaneous plating osteosynthesis technique. Int $\mathbf{J}$ Res Orthop 2016;2(3):132-7.

10. Nithyananth JM, Cherian VM, Lee VN, Sundararaj GD. MIPPO of proximal tibial fractures: Are angled stable implants the only way?. Injury Extra 2008;5(39):203-4.

11. Biggi F, Di Fabio S, D'Antimo C, Trevisani S. Tibial plateau fractures: internal fixation with locking plates and the MIPO technique. Injury 2010;41(11):1178-82.

12. Sharma R, Kapila R, Singh BP, Sohal YS. Traditional buttress plating v/s MIPO in management of proximal tibial fractures-A clinical study. $\mathrm{Pb}$ Journal of Orthopaedics 2013;14(1):11-6.

13. Rohra N, Suri HS, Gangrade K. Functional and radiological outcome of Schatzker type V and VI tibial plateau fracture treatment with dual plates with minimum 3 years follow-up: a prospective study. Journal of clinical and diagnostic research: JCDR 2016;10(5):RC05. 